\title{
IMPACT OF INTESTINAL PARASITES ON HEMATOLOGICAL PARAMETERS AMONG SCHOOL CHILDREN IN GHARBIA GOVERNORATE, EGYPT \\ By
}

\author{
AHMED M. S. BAYOUMY ${ }^{1 *}$, KHAIRY A. M. HASSAN ${ }^{1}$, MORSY R. GENEIDY ${ }^{1}$, \\ and ALAA G. S. METAWEA ${ }^{2}$ \\ Departments of Medical Parasitology, Faculties of Medicine (boys) ${ }^{1}$ and (Damietta) ${ }^{2}$ \\ Al-Azhar University, Egypt ('Correspondence: drahmedbayoumy@azhar.edu.eg)
}

\begin{abstract}
Generally, the intestinal parasites are responsible for morbidity in school-aged children worldwide, especially in undeveloped countries. So a cross sectional random study was conducted from early October, 2017 to late December, 2017 and included 200 children attending primary schools in Gharbia Governorate, Egypt. All cases were subjected to (1) a questionnaire filled out by an interview with the child and/or one of his/her parents. (2) Fresh stool samples were taken for parasitological diagnosis and detection of intestinal parasites by direct smear method, simple floatation and formol-ether concentration techniques. (3) Blood samples were collected for estimation of blood indices (CBC) and serum ferritin level. Among the total 200 (100 males and 100 females) cases included in the present study, 96 (48\%) (47 males and 49 females) were proved to be positive for parasitic infection. The prevalence rate of the intestinal parasites among studied children was; E. histolytica/dispar, 56 cases (58.33\%) which was the most common parasite found. The other infections were: G. lamblia, 8 $(8.33 \%)$ cases, S. mansoni, $6(6.25 \%)$ cases, H. nana, $6(6.25 \%)$ cases, E. vermicularis, $4(4.16 \%)$ cases and poly parasites in16 $(16.66 \%)$ cases. Distribution of hematological indices among children was: Total 110 cases had anemia; 51 males (34 infected and 17 non-infected) and 59 females (38 infected and 21 non-infected). No children had severe anemia and iron store of them was adequate. Among 96 cases infected; 50 cases $(52.08 \%)$ had normocytic normochromic anemia, 22 cases $(22.91 \%)$ had microcytic hypochromic anemia and 24 cases $(25 \%)$ were not anemic. There was a strong association between $G$. lamblia infection and presence of anemia as it was noted that all the 8 infected cases had anemia while 6 cases (75\%) of them showed decrease in serum ferritin level. Among the 56 cases that had E. histolytica/dispar infection, 42 of them were anemic, while among the 6 cases of schistosomiasis mansoni, 4 cases of them were anemic. Regarding the 6 cases infected with $H$. nana, 4 cases of them were anemic while among 16 cases of mixed parasitic infection, only 14 cases were anemic. It was also noted that all the 4 cases suffering from $E$. vermicularis infection were not anemic.

Only 13 cases suffering from parasitic infections had low serum ferritin. Four of them had moderate type while the other 9 children had mild type. Non infected children had normal ferritin level. It is of interest to found that; 3 cases infected with G. lamblia had moderate decrease in serum ferritin level < $8 \mathrm{ng} / \mathrm{ml}$. One case had mixed infection had moderate decrease in serum ferritin level.

In conclusion, the present study showed a high prevalence of intestinal parasitic infection correlated with anemia which calls for a comprehensive public health intervention and regular parasitic screening in school-aged children.
\end{abstract}

Key words: intestinal parasitic infections, school children, blood indices, serum ferritin.

\section{Introduction}

Infection with intestinal parasites is endemic worldwide as a major public health problem among school-aged children in developing countries especially hot and humid environments. (Dash et al, 2010, Oliveira et $a l, 2015)$ where prevalence rates range from $30-60 \%$, as compared to about $2 \%$ in the developed countries (Shubair et al, 2000; Brito et al, 2003).
In Egypt, the prevalence rate was depending on the socio-economic level, poor sanitary and environmental conditions, inadequate personal hygiene, absence of safe drinking water supplies and climatic factors as well as poor housing conditions (Abou El-Soud, 2009; Bayoumy et al, 2016; 2018). Intestinal parasitosis among school children has detrimental effects on the survival, appetite, growth and physical fitness (Ekpen- 
yong, 2008; Jardim-Botelho et al, 2008), school attendance (Nematian et al, 2008) and cognitive performance (WHO, 2006).

Anemia affected half the school-age children and adolescents in developing countries (Huong et al, 2007). It has complex etiological factors, including micronutrient deficiencies (iron, folate, riboflavin, vitamin A \& B12), hemoglobinopathies and parasitic infections (Midzi et al, 2010). Parasitic infections may influence nutritional and iron status by reducing nutrient intake and interfering directly or indirectly with iron absorption and transportation (Yanola et al, 2018). The presence of intestinal parasites was usually parallel with appearance of iron deficiency anemia (Ferreira et al, 2002). In school-aged children, both infections and iron deficiency can lead to anorexia. Infections inhibited the absorption of iron from the gastro-intestinal tract and iron deficiency lowers immunity to infections, which created a vicious circle of inadequate nutrition (Stoltzfus et al, 1997; Olsen et al, 1998).

The present study aimed to determine the prevalence of intestinal parasitic infections among school children in Gharbia Governorate, Egypt and explored the possible relationship between these infections and different hematological parameters and serum ferritin.

\section{Materials, Subjects and Methods}

A cross-sectional random study was conducted on 200 school children aging (6-12 years) attending primary schools in El-Santa City (50 students) and El-Santa villages (150 students) in Gharbia Governorate, Egypt during the period from early October, 2017 to late December, 2017 after permission from the local Education Authority. Exclusive criteria included pupils below 6 years as well as above 12 years, blood diseased and sick, febrile pupils at the time of the study. Also children who had taken anti-helminthic drugs within 6 months of the study or those who received blood transfusion or iron containing medicine within 3 months proceeding to the study were excluded.
All children were subjected to the following: (1) a questionnaire filled out by an interview with the child and/or one of his/her parents. (2) Fresh stool samples were collected in clean, labeled and wide mouthed plastic containers that had tight fitting overlapping lids. (3) Collection of aseptically $3 \mathrm{ml}$ of venous blood samples for complete blood count (CBC) examination using Mindray BC-5800 auto hematology analyzer and another $2 \mathrm{ml}$ of blood were collected for sera extraction. Serum ferritin concentration was analyzed by enzyme-linked immune fluorescent assay using the VIDAS $^{\circledR}$ human ferritin enzyme immunoassay test kit (France).

Stool samples were examined macroscopically and microscopically by: (i) direct wet smear method. (ii) Concentration methods by simple floatation and formol ether concentration techniques (WHO, 1994). The obtained data were tabulated and statistically analyzed.

The study was approved by the Governmental Health and Education Authorities and only children whose parents/guardians signed the informed consent were included in the present work.

\section{Results}

According to age and sex the randomly chosen 200 children were distributed as follows; 50 children aged from 6 to $<8$ years $(23$ males and 27 females), 80 children aged from 8 to $<11$ years ( 39 males and 41 females) and 70 children aged from 11 to 12 years ( 38 males $\& 32$ females). $\chi^{2}=0.884, p$ $=0.643$ (Tab. 1).

Out of 200 stool samples examined, 96 (48\%) were positive for intestinal parasites and the distribution of parasitic infections according to age group was presented as 23/50 pupil aged 6- 8 y were infected and $42 / 80$ pupil aged $8-11$ y were infected while $31 / 70$ pupil aged $11-12$ y were infected; $\chi^{2}=$ $1.116, \mathrm{p}=0.572$ (Tab. 2). Among the students; 51 males had low hemoglobin level compared to 59 females and 47 males have low PCV compared to 48 females while 19 males had low $\mathrm{MCH}$ compared to 7 females 
with a significant differences as to $\mathrm{MCH}$ $(\mathrm{p}=0.01)($ Tab. 3).

Out of 51 anemic males 34 of them were positive for parasitic infection while out of 59 anemic females 38 of them were infected. $\mathrm{P}=0.004, \chi^{2}=11.011^{*}$ (Tab 4). Among the 110 anemic children, 102 of them had hemoglobin level ranging between 10-11.5 $\mathrm{g} / \mathrm{dl}$ and 66 were positive for intestinal parasitic infection compared to 8 pupils who had $8-<10 \mathrm{~g} / \mathrm{dl}$ of hemoglobin and 6 of them were infected. According to type of anemia, 26 children had microcytic hypochromic anemia and 22 of them were positive for intestinal parasitic infection while 84 children had normocytic normochromic anemia and 50 were infected (Tab. 5).

Out of 96 children infected with different intestinal parasites; $72(75 \%)$ were anemic while out of 104 non- infected pupils; 38 (36.5\%) had anemia with significant statistical analysis; $\chi^{2}=29.837, p=0.01$ (Tab. 6). Among the 96 cases having intestinal parasitic infection; 24 (25\%) were not anemic, while $50(52.08 \%)$ had normocytic normochromic anemia and 22 (22.9\%) cases had microcytic hypochromic anemia (Tab. 7).

Among the 56 E. histolytica/dispar cases $42(75 \%)$ were anemic and ten had microcytic hypochromic anemia. Eight giardiasis cases were anemic; six were related to microcytic hypochromic type. Regarding schistosomiasis and hymenolepiasis (6 cases of both), four had normocytic normochromic anemia. Four E. vermicularis cases were not anemic while of mixed infection 14/16 $(87.5 \%)$ were anemic and 6 suffered from microcytic hypochromic anemia; $\chi^{2}=$ 16.444*, $\mathrm{p}=0.006$ (Tab. 8).

Among the 56 E. histolytica; cases 24, 42, 40, 10 \& 10 had low RBCs, Hb\%, PCV, MCV \& MCH ratio respectively. Among 8 G. lamblia cases 4, 8, 6, $6 \& 6$ had low $\mathrm{RBCs}, \mathrm{Hb} \%, \mathrm{PCV}, \mathrm{MCV} \& \mathrm{MCH}$ ratio respectively. Among $6 \mathrm{~S}$. mansoni cases 4, 4 $\& 4$ had low RBCs, $\mathrm{Hb} \%$ and $\mathrm{PCV}$ ratio respectively while among $6 H$. nana cases 2,4 \& 4 had low RBCs, $\mathrm{Hb} \%$ \& PCV ratio respectively. Among 16 mixed parasitic infection cases 4, 14, 14, 6 \& 6 had low RBCs, $\mathrm{Hb} \%$, PCV, MCV \& MCH ratio respectively. Four E. vermicularis cases had normal hematological parameters (Tab. 9).

No significant changes in total leucocytic count, number of lymphocytes, monocytes, neutrophils and basophils between infected and control (Tab.10).

Only the 13 cases suffering from parasitic infections had low serum ferritin. Four of them had moderate type while the other 9 children had mild type. Non infected children had normal ferritin level; $\chi^{2}=15.062^{*}$, $\mathrm{p}=0.01($ Tab. 11).

Three G. lamblia cases had moderate decrease in serum ferritin level $<8 \mathrm{ng} / \mathrm{ml}$. One case had mixed infection had moderate decrease in serum ferritin level; $\chi^{2}=40.640^{*}$, $\mathrm{p}=0.001$ (Tab. 12)

Table 1: Age and sex distribution among studied children

\begin{tabular}{|c|c|c|c|c|c|c|c|}
\hline \multirow{2}{*}{ Age } & \multicolumn{2}{|c|}{$6-<8$ y $50(25 \%)$} & \multicolumn{2}{|c|}{$8-<11$ y $80(40 \%)$} & \multicolumn{1}{c|}{$11-12$ y $70(35 \%)$} & \multirow{2}{*}{ Total } \\
\cline { 2 - 8 } & Male & Female & Male & Female & Male & Female & \multirow{2}{*}{200} \\
\hline No. of cases & 23 & 27 & 39 & 41 & 38 & 32 & \\
\hline$\%$ & $46 \%$ & $54 \%$ & $48.8 \%$ & $51.2 \%$ & $54.3 \%$ & $45.7 \%$ & \\
\hline
\end{tabular}

Table 2: Distribution of parasitic infection among infected children according to age group

\begin{tabular}{|l|c|c|c|c|c|c|c|c|}
\hline \multirow{2}{*}{ Parasite species } & \multicolumn{2}{|c|}{$6-<8$ yo. 50} & \multicolumn{2}{c|}{$8-<11$ y No. 80} & \multicolumn{2}{c|}{$11-12$ y No. 70} & \multicolumn{2}{c|}{ Total } \\
\cline { 2 - 10 } & No. & $\%$ & No. & $\%$ & No. & $\%$ & No. & $\%$ \\
\hline E. histolytica/dispar & 11 & 11.5 & 26 & 27.1 & 19 & 19.8 & 56 & 58.3 \\
\hline G. lamblia & 2 & 2.1 & 4 & 4.2 & 2 & 2.1 & 8 & 8.3 \\
\hline S. mansoni & 0 & 0.0 & 1 & 1.0 & 5 & 5.2 & 6 & 6.3 \\
\hline H. nana & 2 & 2.1 & 3 & 3.1 & 1 & 1.0 & 6 & 6.3 \\
\hline E. vermicularis & 3 & 3.1 & 1 & 1.0 & 0 & 0.0 & 4 & 4.2 \\
\hline Mixed infection & 5 & 5.2 & 7 & 7.3 & 4 & 4.2 & 16 & 16.7 \\
\hline Overall prevalence & 23 & 24 & 42 & 43.7 & 31 & 32.3 & 96 & 100 \\
\hline
\end{tabular}


Table 3: Distribution of the hematological indices among the examined children versus sex

\begin{tabular}{|c|c|c|c|c|c|c|c|c|c|c|}
\hline & \multicolumn{2}{|c|}{ Hemoglobin level } & \multirow[t]{2}{*}{ Total } & \multicolumn{2}{|c|}{ PCV } & \multirow[t]{2}{*}{ Total } & \multicolumn{2}{|c|}{$\mathrm{MCH}$} & \multirow[t]{2}{*}{ Total } \\
\hline & & Low & Normal & & Low & Normal & & Low & Normal & \\
\hline \multirow{2}{*}{ Male } & No. & 51 & 49 & 100 & 47 & 53 & 100 & 19 & 81 & 100 \\
\hline & $\%$ & 51 & 49 & 100 & 47 & 53 & 100 & 19 & 81 & 100 \\
\hline \multirow{2}{*}{ Female } & No. & 59 & 41 & 100 & 48 & 52 & 100 & 7 & 93 & 100 \\
\hline & $\%$ & 59 & 41 & 100 & 48 & 52 & 100 & 7 & 93 & 100 \\
\hline$\chi^{2}$ & \multicolumn{4}{|c|}{1.293} & \multicolumn{3}{|c|}{0.020} & \multicolumn{3}{|c|}{$6.366^{*}$} \\
\hline $\mathrm{P}$ & \multicolumn{4}{|c|}{0.856} & \multicolumn{3}{|c|}{0.887} & \multicolumn{3}{|c|}{0.01} \\
\hline
\end{tabular}

Table 4: Distribution of infection among anemic males and females

\begin{tabular}{|l|c|c|c|c|}
\hline \multirow{2}{*}{ Infection +/- } & \multicolumn{2}{|c|}{ Infected } & \multicolumn{2}{c|}{ Non infected } \\
\cline { 2 - 5 } Anaemic cases & No. & $\%$ & No. & $\%$ \\
\hline Males (No. = 51) & 34 & 66.7 & 17 & 33.3 \\
\hline Females (No. = 59) & 38 & 64.4 & 21 & 35.6 \\
\hline Total (No. = 110) & 72 & 65.5 & 38 & 34.5 \\
\hline
\end{tabular}

Table 5: Correlation between anemic cases and intestinal parasitic infection

\begin{tabular}{|c|c|c|c|}
\hline \multirow{2}{*}{$\begin{array}{c}\text { Hemoglobin } \\
\text { level }\end{array}$} & $8-<10 \mathrm{gm} / \mathrm{dl}$ & Anemic cases $(\mathrm{N}=110)$ & Positive parasitic cases $(\mathrm{N}=72)$ \\
\cline { 2 - 4 } & $10-11.5 \mathrm{gm} / \mathrm{dl}$ & 102 & 6 \\
\hline \multirow{2}{*}{$\begin{array}{c}\text { Type of } \\
\text { anemia }\end{array}$} & Microcytic hypochromic & 26 & 66 \\
\cline { 2 - 4 } & Normocytic Normochromic & 84 & 50 \\
\hline
\end{tabular}

Table 6: Distribution of anemia among infected and non-infected children

\begin{tabular}{|c|c|c|c|c|c|c|}
\hline & \multicolumn{2}{|c|}{ Anemic } & \multicolumn{2}{c|}{ Normal } & Total & \\
\cline { 2 - 6 } & No. & $\%$ & No. & $\%$ & No. & $\%$ \\
\hline Infected cases $(\mathrm{N}=96)$ & 72 & 75.0 & 24 & 25.0 & 96 & $100 \%$ \\
\hline Non infected cases $(\mathrm{N}=104)$ & 38 & 36.5 & 66 & 63.5 & 110 & $100 \%$ \\
\hline Total $(\mathrm{N}=200)$ & 110 & 55.0 & 90 & 45.0 & 200 & $100 \%$ \\
\hline
\end{tabular}

Table 7: Distribution of type of anemia among infected children

\begin{tabular}{|l|c|c|}
\hline \multicolumn{2}{|c|}{ Anemia (Absent / Present) } & Positive cases (96) \\
\hline Non anemic & $24(25 \%)$ \\
\hline \multirow{2}{*}{ Anemic } & Normocytic normochromic anemia & $50(52.08 \%)$ \\
\cline { 2 - 3 } & Microcytic hypochromic anemia & $22(22.9 \%)$ \\
\hline
\end{tabular}

Table 8: Distribution of anemia among infected children

\begin{tabular}{|l|c|c|c|c|}
\hline \multirow{2}{*}{ Parasite } & \multirow{2}{*}{$\begin{array}{c}\text { Positive } \\
\text { cases }\end{array}$} & Normocytic normochromic & Microcytic hypochromic & Total \\
\cline { 3 - 5 } & 56 & 32 & 10 & $42(75 \%)$ \\
\hline E. histolytica/dispar & 8 & 2 & 6 & $8(100 \%)$ \\
\hline S. lamblia mansoni & 6 & 4 & 0 & $4(66.7 \%)$ \\
\hline H. nana & 6 & 4 & 0 & $4(66.7 \%)$ \\
\hline E. vermicularis & 4 & 0 & 0 & $0(0 \%)$ \\
\hline Mixed infection & 16 & 8 & 6 & $14(87.5 \%)$ \\
\hline Total no. & 96 & 50 & 22 & $72(75 \%)$ \\
\hline
\end{tabular}

Table 9: Average levels of erythrocytes, hemoglobin levels, PCV, MCV and MCH among infected individuals

\begin{tabular}{|c|c|c|c|c|c|c|c|c|c|c|c|}
\hline \multirow{2}{*}{ Parasite } & \multirow{2}{*}{$\begin{array}{l}\text { No. of } \\
\text { cases }\end{array}$} & \multicolumn{2}{|c|}{ RBCs } & \multicolumn{2}{|c|}{$\mathrm{Hb} \%$} & \multicolumn{2}{|c|}{ PCV } & \multicolumn{2}{|c|}{$\mathrm{MCV}$} & \multicolumn{2}{|c|}{$\mathrm{MCH}$} \\
\hline & & $\mathrm{N}$ & $\mathrm{L}$ & $\mathrm{N}$ & $\mathrm{L}$ & $\mathrm{N}$ & $\mathrm{L}$ & $\mathrm{N}$ & $\mathrm{L}$ & $\mathrm{N}$ & $\mathrm{L}$ \\
\hline E. histolytica/disper & 56 & 32 & 24 & 14 & 42 & 16 & 40 & 46 & 10 & 46 & 10 \\
\hline G. lamblia & 8 & 4 & 4 & 0 & 8 & 2 & 6 & 2 & 6 & 2 & 6 \\
\hline S. mansoni & 6 & 2 & 4 & 2 & 4 & 2 & 4 & 6 & 0 & 6 & 0 \\
\hline H. nana & 6 & 4 & 2 & 2 & 4 & 2 & 4 & 6 & 0 & 6 & 0 \\
\hline E. vermicularis & 4 & 4 & 0 & 4 & 0 & 4 & 0 & 4 & 0 & 4 & 0 \\
\hline Mixed infection & 16 & 12 & 4 & 2 & 14 & 2 & 14 & 10 & 6 & 10 & 6 \\
\hline \multirow{2}{*}{ Chi-square test } & $\chi^{2}$ & \multicolumn{2}{|c|}{$6.596^{*}$} & \multicolumn{2}{|c|}{$16.444 *$} & \multicolumn{2}{|c|}{$12.043^{*}$} & \multicolumn{2}{|c|}{$21.081 *$} & \multicolumn{2}{|c|}{$19.780 *$} \\
\hline & $\mathrm{P}$ & \multicolumn{2}{|c|}{0.252} & \multicolumn{2}{|c|}{0.006} & \multicolumn{2}{|c|}{0.034} & \multicolumn{2}{|c|}{0.001} & \multicolumn{2}{|c|}{0.001} \\
\hline
\end{tabular}

$\mathrm{N}=$ Normal, $\mathrm{L}=$ Low, No. $=$ number 
Table 10: Average levels of WBCs, eosinophils, basophils, monocytes, lymphocytes and neutrophils in infected \& noninfected children

\begin{tabular}{|c|c|c|c|c|c|c|c|c|c|c|c|c|}
\hline & \multicolumn{2}{|c|}{ WBCs } & \multicolumn{2}{|c|}{ Eosinophils } & \multicolumn{2}{|c|}{ Basophils } & \multicolumn{2}{|c|}{ Monocytes } & \multicolumn{2}{|c|}{ Lymphocytes } & \multicolumn{2}{|c|}{ Neutrophils } \\
\hline & No. & high & No. & high & No. & high & No. & high & No. & high & No. & high \\
\hline Non infected (104) & 102 & 2 & 104 & 0 & 104 & 0 & 104 & 0 & 104 & 0 & 104 & 0 \\
\hline Infected (96) & 92 & 4 & 65 & 31 & 94 & 2 & 96 & 0 & 78 & 18 & 84 & 12 \\
\hline \multirow[t]{2}{*}{ Chi-square test } & $\chi^{2}$ & 0.864 & \multicolumn{2}{|c|}{$39.744 *$} & \multicolumn{2}{|c|}{2.109} & \multicolumn{2}{|c|}{-} & \multicolumn{2}{|c|}{$21.429 *$} & \multicolumn{2}{|c|}{$13.830 *$} \\
\hline & $\mathrm{P}$ & 0.353 & \multicolumn{2}{|c|}{0.01} & \multicolumn{2}{|c|}{0.139} & \multicolumn{2}{|c|}{ - } & \multicolumn{2}{|c|}{0.01} & \multicolumn{2}{|c|}{0.01} \\
\hline
\end{tabular}

Table 11: Comparison of serum ferritin levels between non-infected and infected children

\begin{tabular}{|c|c|c|c|c|c|c|c|c|}
\hline & \multicolumn{2}{|c|}{ Normal } & \multicolumn{2}{|c|}{ Moderate decrease } & \multicolumn{3}{c|}{ Mild decrease } & \multicolumn{3}{c|}{ Total } \\
\hline & No. & $\%$ & No. & $\%$ & No. & $\%$ & No. & $\%$ \\
\hline Non infected $(\mathrm{n}=104)$ & 104 & 100 & 0 & 0 & 0 & 0 & 104 & 100 \\
\hline Infected $(\mathrm{n}=96)$ & 83 & 86.5 & 4 & 4.2 & 9 & 9.4 & 96 & 100 \\
\hline
\end{tabular}

Mild decrease in s. ferritin level $=10-20 \mathrm{ng} / \mathrm{ml}$, Moderate decrease in s. ferritin level $<10 \mathrm{ng} / \mathrm{ml}$

Table 12: Effect of different intestinal parasites on serum ferritin level

\begin{tabular}{|c|c|c|c|c|c|c|}
\hline \multirow{2}{*}{ Detected intestinal parasites } & \multicolumn{2}{|c|}{ Normal } & \multicolumn{2}{|c|}{ Moderate decrease } & \multicolumn{2}{|c|}{ Mild decrease } \\
\hline & No. & $\%$ & No. & $\%$ & No. & $\%$ \\
\hline E. histolytica /dispar $(\mathrm{n}=56)$ & 54 & 96.4 & 0 & 0.0 & 2 & 3.6 \\
\hline G. lamblia $(\mathrm{n}=8)$ & 2 & 25.0 & 3 & 37.5 & 3 & 37.5 \\
\hline S. mansoni $(\mathrm{n}=6)$ & 5 & 83.3 & 0 & 0.0 & 1 & 16.7 \\
\hline H. nana $(\mathrm{n}=6)$ & 6 & 100.0 & 0 & 0.0 & 0 & 0.0 \\
\hline E. vermicularis $(\mathrm{n}=4)$ & 4 & 100.0 & 0 & 0.0 & 0 & 0.0 \\
\hline Mixed infection $(n=16)$ & 12 & 75.0 & 1 & 6.25 & 3 & 18.8 \\
\hline Total $(\mathrm{n}=96)$ & 83 & 86.5 & 4 & 4.2 & 9 & 9.38 \\
\hline \multirow[t]{2}{*}{ Chi-quasre test } & $\chi^{2}$ & $40.640 *$ & & & & \\
\hline & $\mathrm{P}$ & 0.001 & & & & \\
\hline
\end{tabular}

\section{Discussion}

Intestinal parasitic infections still constitute one of the major causes of public health problems in the world, particularly in developing countries (Ekpenyong, 2008). Geographic and socioeconomic conditions, climate, poverty, malnutrition, personal and community hygiene, population density, unavailability of drinking water as well as poor sanitary facilities are the factors affecting the prevalence rate (Bdir and Adwan, 2010). The infections are more common and tend to be of high intensity among school age children ranged between 6-14 years (Sharma et al, 2004; Ekpenyong, 2008) which affect their physical development, school attendance and ability to learn (Jasti et al, 2007).

The present study investigated the impact of intestinal parasites on hematological parameters (complete blood count and serum ferritin level) of school-age children in both urban and rural communities in Gharbia Governorate, Egypt.

Forty eight $(48 \%)$ percent of the children were identified as having one or more of the following parasites present in their stool samples: E. histolytica/dispar, G. lamblia, S. mansoni, H. nana, E. vermicularis and $A$. lumbricoides which agrteed with Zaglool et al (2011) in Saudi Arabia, Oliveira et al (2015) in Angola and Yanola et al (2018) in Turkey. This was higher than (Ibrahium, 2011 and Bayoumy et al, 2016; 2018) who reported that parasitic prevalence among Egyptian school children in El-Minia, El Wadi El Gadeed and El Beheira Governorates were $29.3 \% 39.1 \%$ \& $38.3 \%$ respectively.

However, the present results were less than that reported in Upper Egypt by El-Masry et al. (2007) who reported parasitic infections among Egyptian school children in Tamouh and rural school students in Sohag Governorate villages were $60.2 \%$ \& $88.5 \%$, respectively. These differences could be attributed to the locations of the studies, the season of the year the study was carried out and the method of stool analysis.

The distributions of hematological indices according to sex revealed that anemia was more prevalent among females in contrary to similar study by Oluwafemi and Oguntibeju (2003) and Le et al (2007) who showed percentage of anemia was more in males than females. The overall prevalence rate of anemia among the children was high (55\%) and were anemic $(\mathrm{Hb}<11.5 \mathrm{gm} / \mathrm{dl})$. This agreed 
with Kulsum et al. (2013) who found that, out of 700 blood samples examined from studied Indian children 399 (57\%) were anemic and also agreed with Adebara et al. (2011) who reported that, more than a third of the Nigerian school children had Hb levels less than $11 \mathrm{~g} / \mathrm{dl}$ and higher than Le et al (2007) and Oliveira et al (2015) who found that, prevalence of anemia among school children in rural Vietnam and Angola was $25 \% \& 21.6 \%$ respectively. Non child had severe anemia which agreed with Adewuyi et al. (1992) and Adebara et al. (2011). The mean haemoglobin value was higher than results obtained in studies (Akinkugbe, 1977; Kulsum et al, 2013).

In the present study there was relationship between anemia and parasitic infections especially in G. lamblia, E. histolytica/dispar, $S$. mansoni and $H$. nana which agreed with Hendrickse (1991) and Shanti and Ghosh (2004). Among the most prevalent protozoa found was $G$. lamblia which observed among $100 \%$ of anemia while $75 \%$ had microcytosis and hypochromia. This percentage was higher than that reported by Carrilho et al (2011) as they found that of $80 \mathrm{G}$. lamblia patients only $21(26.3 \%)$ had anemia. Also, Sackey et al (2003) reported that $26.4 \%$ of the Ecuadorian children had iron deficiency anemia and those with G. intestinalis infection exhibited significantly reduced mean serum hemoglobin levels compared to parasite-free ones. Also, association of Giardia with reduced serum hemoglobin was not correlated with age.

G. lamblia infection depends on the pathogenesis, the host immune and the activated proteases (Ma'ayeh et al, 2017). The interaction of the intestinal tract with the protozoa is also an important factor, where among the adverse effects, probably stimulated by the infection are villous atrophy in various degrees in the small intestine, associated with inflammatory infiltrate and crypt hypertrophy; bile acids alterations and decreased the disacaridases activity (Crua, 2003). As a consequence of these mechanisms, patient has poor absorption of sugars, fats, vitamins A, D, E, K, B12, folic acid, iron and zinc (Rey, 2001). This poor absorption of iron described may explain the high percentage of anemia among individuals infected by $G$. lamblia in the present work. In the present work, the negative impact of giardiasis on child iron status agreed with Shubair et al. (2000) who linked giardiasis with significantly reduced mean hemoglobin level in Palestinian and Egyptian children.

Comparison of the haematological status

between infected and non-infected children showed that the mean hemoglobin indices of the latter were higher. This agreed with Curtale et al. (2000) in Alexandria, Yentur Doni et al. (2014) in Turkey and Oliveira et al. (2015) in Angola. The association between low hemoglobin and parasitic positivity was possible because intestinal parasites were lodged in the duodenum and jejunum, the iron absorption site (Alfred $e t$ al, 2013).

The present work showed that lecocytosis (mainly eosinophilia) in infected cases as compared to non-infected persons. This agreed with the results of Yanola et al. (2018) who showed increase number of W.B.Cs (10.6) $\times 10^{3}$ cell $/ \mathrm{mm}^{3}$ in infected cases in comparison with control (6.31) $\mathrm{x}$ $10^{3}$ cell $/ \mathrm{mm}^{3}(74.7 \%)$. This may be due to the eosinophils ability to destroy parasites by attaching to its wall and secretion of granules leading to their destruction. Low $6.5 \%$ of children having low serum ferritin level indicated iron deficiency anemia among them. Iron store of studied population was adequate with only $6.5 \%$ had exhausted iron stores. Serum ferritin increased during infection, giving false negative results for iron deficiency (Lipschitz et al, 1974). A higher cut-off value for serum ferritin to determine iron deficiency in infected populations and/or inflammatory diseases was highly prevalent (Punnonen and Irjala, 1997).

In the present study, there was a significant association between serum ferritin values 
and parasitosis. Six G. lamblia cases had low serum ferritin level and exhausted iron stores. This was at variance with studies done in other parts of Africa (Stoltzfus et al, 1997; Olsen et al, 1998) where the exhausted iron stores degree was higher. This could be attributed to low hookworm cases in the present study. Adebara et al. (2011) found association between intestinal helminthiasis and serum ferritin level among Nigerian school children and reported that ferritin levels were lower in hookworm children. Also, $36 \%$ of hookworm pupils had exhausted iron stores. But, neither A. lumbricoides nor $T$. trichiura was related to any iron deficiency.

\section{Conclusion}

The high prevalence of intestinal parasitic infection and anemia observed in this study calls for a comprehensive public health intervention. There is a strong need for helminthes control as a strategy to control iron deficiency in the school children where anthelminthic drugs are safe and cheap and giving as periodic delivery to them.

\section{References}

Abou El-Soud, FA, Salama, RA, Taha, NS, 2009: Predictors of the intestinal parasitic infection among pre-school children in rural lower, Egypt. Egypt. J. Commun. Med. 27:17-34. Adebara, OV, Samuel, KE, Isaac, AO, 2011: Association between intestinal helminthiasis and serum ferritin levels among school children. Open J. Pediatr. 1:12-16.

Adewuyi, JO, 1992: Current prevalence and some clinical associations of childhood anemia in urban communities in central Nigeria. Cen. Afri. J. Med. 38:66-72.

Akinkugbe, FM, 1977: Prevalence of anemia in an urban population (University College Hospital GOPD). J. Trop. Ped. Environ. Child. Hlth. 23:271-5.

Alfred, FE, Youtchou, MT, Joy, IE, Uhuonrenren, O, 2013: Hemoglobin concentration of intestinal parasites infected children in Okada, Edo state, Nigeria. Open J. Epidemiol. 3:149-52. Bayoumy, AMS, Abd El Raheem, MA, Abo Hashim, AH, Al Saadawy, AS et al, 2018: Parasitic profile among primary school children in a rural area at Beheira Governorate, Egypt. Egypt. J Hosp. Med. 70:2042-9
Bayoumy, AMS, Ibrahim, WLF, Abou El-Nour, BM, Said, AAA, 2016: The Parasitic profile among school children in El-Wadi El-Gadded Governorate, Egypt. J. Egypt. Soc. Parasitol. 46: 605-12.

Bdir, S, Adwan, G, 2010: Prevalence of intestinal parasitic infections in Jenin Governorate. Palestine: a 10-year retrospective study. Asian Pac. J. Trop. Med. 745-7.

Brito, LL, Barreto, ML, Silva, RC, Assis, A M, Reis, MG, et al, 2003: Risk factors for irondeficiency anemia in children and adolescents with intestinal helminthic infection. Rev. Panam Sal. Publ. 14:122-131.

Carrilho, G, Olivi, MJ, Vicentini, V, DA Costa, GM, Anibal, F, 2011: Anemia in patients with intestinal parasitic infection. Rev. IberoLatinoam. Parasitol. 70:206-11.

Crua, AS, 2003: Parasitosis intestinalis. In: Ferreira CT, Carvalho E, Silva LR,.eds. Gastroenterologia e Hepatologia em pediatria: diagnostic e tratamento. Rio de Janeiro: Medsi 185-97.

Curtale, F, Abdel-Fattah, M, El-Shazly, M, Shamy, MY, El-Sahn, F, 2000: Anemia among young male workers in Alexandria, Egypt. East Mediterr. Hlth. J. 6. 5/6:1005-16

Dash, N, Al-Zarouni, M, Anwar, K, Panigrahi, D, 2010: Prevalence of intestinal parasitic infections in Sharjah, United Arab Emirates. Human Parasit. Dis. 2:21.

Ekpenyong, E 2008: Prevalence of intestinal helminthes infections among schooling children in tropical semi urban communities. Anim. Res. Int. 5:804-10.

El-Masry, FA, El-Hawary, ZM, Salem, NA, 2007: Competing anemia among school children using a highly available on preparation. Egypt. J. Comm. Med. 7, 2:81-94.

Ferreira, HS, Assuncao, ML, Vasconelos, VS, Melo, FP et al, 2002: Saúde de populações marginalizadas: desnutrição, anemia e enteroparasitoses em crianças de uma favela do "Movimento dos Sem Teto", Maceió, Alagoas 2, 2:177-85.

Hendrickse, RG, 1991: Parasitic diseases. In: Pediatrics in Tropics. Hendrickse RG, Barr DG D, Matthews IS, $1^{\text {st }}$ Ed., Oxford, Blackwell Scientific Publications.

Huong, L, Brouwer, ID, Verhoef, H, Nguyen, KC, Kok, FJ, 2007: Anemia and intestinal parasite infection in school children in rural Vietnam. Asian Pac. J. Clin. Nutr. 16, 4:716-23.

Ibrahim, AA, 2011: Prevalence and predisposing factors regarding intestinal parasitic infec- 
tions among rural primary school pupils at Minia Governorate, Egypt. J. Publ. Hlth. Afri. 2:29-32.

Jardin-Botelho, A, Brooker, S, Geiger, S, Fleming, F, et al, 2008: Age patterns in undernutrition and helminth infection in a rural area of Brazil: associations with ascariasis and hook worm. Trop. Med. Int. Hlth. 13:458-67.

Jasti, A, Ojha, SC, Singh, YI, 2007: Mental and behavioral effects of parasitic infections: a review. Nepal Med. Coll. J. 9, 1:50-6.

Kulsum, SN, Andra, C, Nawaz, U, 2013: Study of incidence and spectrum of intestinal parasitic infection using formalin ethyl acetate sedimentation technique among children and its correlation with anemia. Biomed. Pharmacol. J. 6, 2:321-30.

Le, HT, Brower, ID, Verhoef, H, Nguyen, $K$ C, Kok, F 2007: Anemia and intestinal infection among school children in rural Vietnam. Asian Pac. J. Clin. Nut. 16, 4:716-23.

Lipschitz, D, Cook, JD, Finch, C 1974: Clinical evaluation of serum ferritin as an index of iron stores. N. Engl. J. Med. 290:1213-16.

Ma'ayeh, SY, Liu, J, Peirasmaki, D, Hörnaeus, K, et al, 2017: Characterization of Giardia intestinalis secretome during interaction with human intestinal epithelial cells: The impact on host cells. PLoS Negl. Trop. Dis. 11, 12:1-41

Midzi, N, Mtapuri, S, Mapingure, M, Sangweme, D et al, 2010: Consequences of poly parasitism on anemia among primary school children in Zimbabwe. Acta Trop. 115:103-11

Nematian, J, Gholamrezanezhad, A Nematian, E 2008: Giardiasis and other intestinal parasitic infections in relation to anthropometric indicators of malnutrition: A large, populationbased survey of school children in Tehran. Ann. Trop. Med. Parasitol. 102:209-14.

Oliveira, D, Ferreira, F, Atouguia, J, Fortes, F et al, 2015: Infection by intestinal parasites, stunting and anemia in school-aged children from Southern Angola. PLOS One 15:1-10

Olsen, A, Magnussen, P, Ouma, JH, Friis, H, 1998: The contribution of hookworm and other parasitic infections to haemoglobin and iron status among children and adults in western Kenya. Trans. R. Soc. Trop. Med. Hyg. 92:643-9

Oluwafemi, O, Oguntibeju, A, 2003: Parasitic infestation and anemia: The prevalence in a rural hospital setting. J. Ind. Acad. Clin. Med. 4, 3: 281-7.
Punnonen, K, Irjala, K, 1997: Serum transferrin receptor and its ratio to serum ferritin in the diagnosis of iron deficiency. Blood 89, 3:10527.

Rey, L, 2001: Parasitologia: Parasitos e doenças parasitárias do homem nas Américas e na África Rio de Janeiro. Guana. Koogan. 8:56.

Sackey, ME, Weigel, MM, Armijos, RX, 2003: Predictors and nutritional consequences of intestinal parasitic infections in rural Ecuadorian children. J. Trop. Pediatr. 49:17-23.

Shanti, S, Ghosh, DS, 2004: Nutritional problems in urban slum children. Ind. Pediatr. 41: 682-96.

Sharma, BK, Rai, SK, Rai, DR, Choudhury, DD, 2004: Prevalence of intestinal parasitic infection in school children in the northeastern part of Kathmandu Valley, Nepal. Southeast Asian J. Trop. Med. Publ. Hlth. 35:501-5.

Shubair, ME, Yassin, MM, Al-Hindi, AI, AlWahaidi, AA, Jadallah SY et al, 2000: Intestinal parasites in relation to haemoglobin level and nutritional status of school children in Gaza. J. Egypt. Soc. Parasitol. 30:365-75.

Stoltzfus, RJ, Chwaya, HM, Tielsch, JM, Schulze, KJ, 1997: Epidemiology of iron deficiency anaemia in Zanzibar schoolchildren: Importance of hookworms. Am. J. Clin. Nutr. 65:153-9.

WHO, 1994: Bench aids for the diagnosis of intestinal parasites. Geneva.

WHO, 2006: Preventive chemotherapy in human helminthiasis (Manual). Preventive Chemotherapy and Transmission Control (PCT), Department of Control of Neglected Tropical.

Yanola, J, Nachaiwieng, W, Duangmano, S, Prasannarong, $\mathrm{M}$ et al, 2018: Current prevalence of intestinal parasites and their impact on hematological and nutritional status among Karen hill tribe children in Omkoi District Mai Province, Thailand. Acta Trop. 180:1-6.

Yentur Doni, N, Yidiz-Zeyrek, F, Simsek, Z, Zeyrek, D 2014: The effects of intestinal parasites on anemia of children. Turki. Parazitol. Derg. 38, 2:85-90

Zaglool, DA, Khodari, YA, Zohair, J, Gazzaz $Z, e t$ al, 2011: Prevalence of intestinal parasites among patients of Al-Noor specialist hospital, Makkah, Saudi Arabia. Oman Med. J. 26, 3:182-5 . 